\title{
Stevens Johnson Syndrome and Toxic Epidermal Necrolysis Induced by Nevirapine among HIV-Infected Pregnant Women: Five Cases
}

Boubacar Ahy Diatta*, Omar Gassama, Saer Diadie, Moussa Diallo, Suzanne Oumou Niang, Maodo Ndiaye, Assane Diop, Fatimata Ly and Mame Thierno Dieng

Cheikh Anta Diop University of Dakar, Senegal

\begin{abstract}
Introduction: The nevirapine is the most widely accused drug in toxidermias in patients living with HIV. It is responsible for toxic epidermal necrolysis called Lyell syndrome or Stevens Johnson syndrome, severe during pregnancy. We report five cases in pregnant women who are HIV-positive.

Case reports: Five pregnant women aged 35 years on average with a mean gestational age of 29.6 weeks of amenorrhea were HIV1-positive. The mean CD4 count was $416 / \mathrm{mm}^{3}$. They had severe toxidermia such as Lyell syndrome or Stevens Johnson syndrome. These toxidermias appeared on average 26 days after taking antiretroviral triple therapy including nevirapine as part of the prevention of mother-to-child transmission of HIV (PMTCT). The outcome was favorable after discontinuation of antiretrovirals. Nevirapine was substituted with lopinavir/ritonavir. Newborns had received antiretroviral prophylaxis and were not infected with HIV.
\end{abstract}

Conclusion: The nevirapine toxidermia is common during antiretroviral therapy. These toxidermia are severe during pregnancy related to maternal and fetal vital risks. The replacement of nevirapine with an anti-protease is a therapeutic alternative in our resource-limited countries.

\section{Keywords: Toxidermia; HIV; Pregnancy; Nevirapine}

\section{Introduction}

Antiretroviral therapy has greatly improved the mortality rate and risk of mother-to-child transmission of human immunodeficiency virus (HIV) infection in resource-limited countries [1]. However, studies have reported the frequency of some risk factors in the occurrence of toxidermia in patients living with HIV. These factors are female, CD4 $>250 / \mathrm{mm}^{3}$ and viral load $>10000$ copies [2]. Nevirapine is the most widely accused drug in these toxidermia $[2,3]$. It is responsible for toxic epidermal necrolysis (TEN) called Lyell syndrome characterized by necrotic bullous eruption greater than $30 \%$ of body surface area and drug reaction with oesinophilia and systemic symptoms (DRESS) [2-4]. The occurrence of these medicinal side effects during pregnancy may involve the maternal and fetal prognosis [5]. We report five cases of toxidermia such as Lyell syndrome or Stevens Johnson syndrome (TEN/SJS) induced by nevirapine in HIV-positive pregnant women.

\section{Case Reports}

\section{Case 1}

A 35 year-old pregnant woman, with 34 weeks of amenorrhea of gestational age, was HIV1-positive with a CD4 count of $280 / \mathrm{mm}^{3}$. It had a necrotic bullous eruption of more than $50 \%$ of the body surface, with involvement of the oral mucosa (Figure 1) and conjunctival hyperemia. This rash occurred 30 days after taking antiretrovirals (zidovudine $300 \mathrm{mg}+$ lamivudine $150 \mathrm{mg}$ and nevirapine $200 \mathrm{mg}$ ) as part of PMTCT. Leukocytes were at $7000 / \mathrm{mm}^{3}$, hemoglobin at $13 \mathrm{~g} /$ $\mathrm{dl}$, platelets at $250.000 / \mathrm{mm}^{3}$, C-reactive protein was positive at 96 $\mathrm{mg} / \mathrm{l}$. Blood ionogram, urea, creatinine, hepatic transaminases and blood glucose were normal. Nevirapine was the incriminating drug. The outcome was favorable in 4 weeks with hyper pigmented scars (Figure 2). The newborn had received antiretroviral prophylaxis and was not infected with HIV. Nevirapine was substituted with lopinavir/ritonavir.

\section{Case 2}

A 35 year old pregnant woman with 34 weeks of amenorrhea of gestational age was HIV1-positive with a CD4 count of $400 / \mathrm{mm}^{3}$. It had a necrotic bullous eruption at $28 \%$ of body surface area with oral mucosa and conjunctival hyperemia. This rash occurred 30 days after taking antiretroviral drugs (zidovudine $300 \mathrm{mg}+$ lamivudine 150 $\mathrm{mg}+$ nevirapine $200 \mathrm{mg}$ ) as part of PMTCT. Anemia at $7.3 \mathrm{~g} / \mathrm{dl}$ was noted and hepatic cytolysis. Nevirapine was the incriminated drug. The outcome was favorable in 3 weeks with hyper pigmented scars. The level of hemoglobin and transaminases had become normal. The newborn had received antiretroviral prophylaxis and was not infected with HIV. Nevirapine was substituted with lopinavir/ritonavir.

\section{Case 3}

A 21 year old pregnant woman with 30 weeks of amenorrhea of gestational age was HIV1-positive with a CD4 count of $500 / \mathrm{mm}^{3}$. It had a necrotic bullous eruption of less than $10 \%$ of body surface area with oral mucosa and conjunctival hyperemia. This rash occurred 28 days after taking antiretrovirals (zidovudine $300 \mathrm{mg}+$ lamivudine 150 $\mathrm{mg}$ and nevirapine $200 \mathrm{mg}$ ) as part of PMTCT. Biological explorations were normal. Nevirapine was the incriminating drug. The outcome was favorable in 3 weeks with hyper pigmented scars. The newborn

*Corresponding author: Boubacar Ahy Diatta, Department of Dermatology of the Cheikh Anta Diop University of Dakar, 30, avenue Pasteur BP: 16520 Dakar, Senegal; Tel: +221775107283; E-mail: ahydiatta@yahoo.com

Received August 11, 2017; Accepted August 19, 2017; Published August 26 , 2017

Citation: Diatta BA, Gassama O, Diadie S, Diallo M, Niang SO, et al. (2017) Stevens Johnson Syndrome and Toxic Epidermal Necrolysis Induced by Nevirapine among HIV-Infected Pregnant Women: Five Cases. J AIDS Clin Res 8: 724. doi: 10.4172/2155-6113.1000724

Copyright: @ 2017 Diatta BA, et al. This is an open-access article distributed under the terms of the Creative Commons Attribution License, which permits unrestricted use, distribution, and reproduction in any medium, provided the original author and source are credited. 
Citation: Diatta BA, Gassama O, Diadie S, Diallo M, Niang SO, et al. (2017) Stevens Johnson Syndrome and Toxic Epidermal Necrolysis Induced by Nevirapine among HIV-Infected Pregnant Women: Five Cases. J AIDS Clin Res 8: 724. doi: 10.4172/2155-6113.1000724

Page 2 of 3

\begin{tabular}{|c|c|c|c|c|c|c|c|c|c|}
\hline Case & Age (Year) & GA (WA) & Type of HIV & $\mathrm{CD} 4\left(\mathrm{~mm}^{3}\right)$ & $\begin{array}{c}\text { Clinical } \\
\text { form }\end{array}$ & Drug inducer & TO (Days) & Outcome & Substitution \\
\hline Case 1 & 35 & 34 & HIV1 & 280 & TEN & NVP & 30 & Favorable & LPV/RTV \\
\hline Case 2 & 35 & 34 & HIV1 & 400 & OS & NVP & 30 & Favorable & LPV/RTV \\
\hline Case 3 & 21 & 30 & HIV1 & 500 & SJS & NVP & 28 & Favorable & LPV/RTV \\
\hline Case 4 & 28 & 30 & HIV1 & 400 & SJS & NVP & 21 & Favorable & LPV/RTV \\
\hline Case 5 & 26 & 20 & HIV1 & 500 & OS & NVP & 21 & Favorable & LPV/RTV \\
\hline
\end{tabular}

TEN: Toxic Epidermal Necrolysis; SJS: Stevens Johnson Syndrome; OS: Overlap Syndrome; NVP: Nevirapine; GA: Gestational Age; WA: Week of Amenorrhea; TO: Time of Occurrence; LPV/RTV: Lopinavir/Ritonavir

Table 1: Summary of cases.

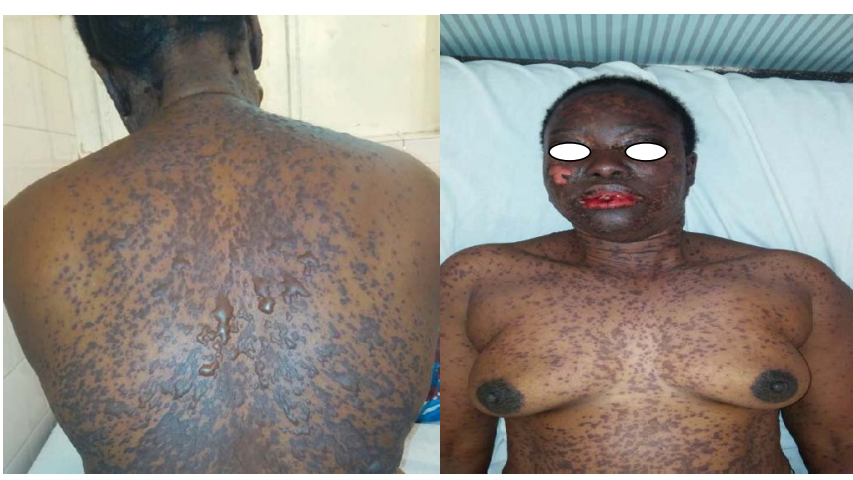

Figure 1: A necrotic bullous rash of more than $50 \%$ of the body surface, with mucosal involvement.

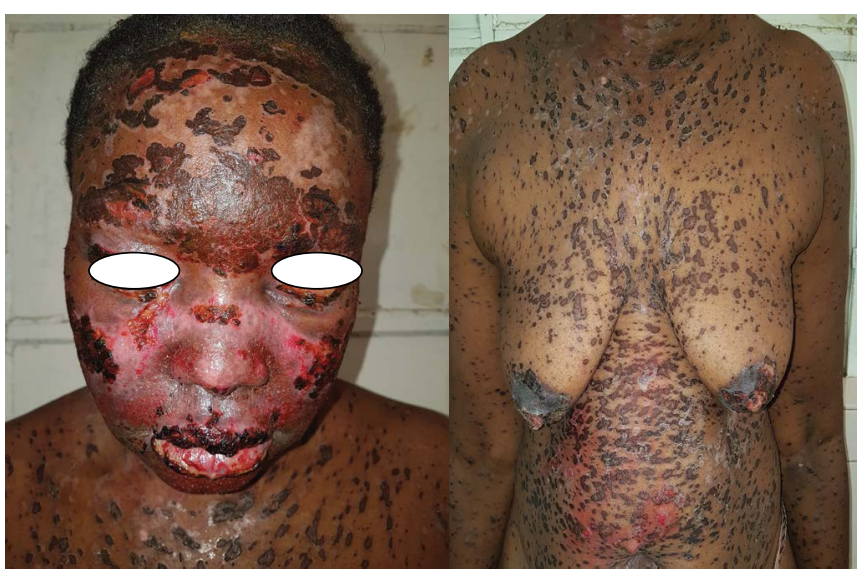

Figure 2: Hyper pigmented macula of trunk and face.

had received antiretroviral prophylaxis and was not infected with HIV. Nevirapine was substituted with lopinavir/ritonavir.

\section{Case 4}

A 28 year old pregnant woman with 30 weeks of amenorrhea of gestational age was HIV1-positive with a CD4 count of $400 / \mathrm{mm}^{3}$. It had a necrotic bullous eruption of less than $10 \%$ of body surface area with involvement of the oral mucosa and conjunctival hyperemia. This rash occurred 21 days after taking antiretrovirals (zidovudine 300 mg+lamivudine $150 \mathrm{mg}$ and nevirapine $200 \mathrm{mg}$ ) as part of PMTCT. Biological explorations were normal. Nevirapine was the incriminating drug. The outcome was favorable in 3 weeks with hyper pigmented scars. The newborn had received antiretroviral prophylaxis and was not infected with HIV. Nevirapine was substituted with lopinavir/ritonavir.

\section{Case 5}

A 26 year old pregnant woman with 30 weeks of amenorrhea of gestational age was HIV1-positive with a CD4 count of $500 / \mathrm{mm}^{3}$. It had a necrotic bullous eruption of less than $28 \%$ of the body surface with oral mucosa and conjunctival hyperemia. This rash occurred 21 days after taking antiretrovirals (zidovudine $300 \mathrm{mg}$ +lamivudine 150 $\mathrm{mg}$ and nevirapine $200 \mathrm{mg}$ ) as part of PMTCT. Nevirapine was the incriminating drug. The outcome was favorable in 3 weeks with hyper pigmented scars. The newborn had received antiretroviral prophylaxis and was not infected with HIV. Nevirapine was substituted with lopinavir/ritonavir.

\section{Discussion}

We report 5 cases of toxidermia characterized by their occurrence in young pregnant women who are HIV positive with an average CD4 count of $416 / \mathrm{mm}^{3}$. They had severe clinical forms such as Lyell syndrome and Stevens Johnson syndrome. Nevirapine was the most implicated drug. The outcome was favorable under symptomatic treatment and discontinuation of antiretrovirals with newborns not infected with HIV (Table 1). Nevirapine toxicity is common [6,7]. Control studies have reported that pregnancy is a risk factor for TEN/SJS when HIV-positive women are treated with a combination of nevirapine with an odds ratio of 14.28 ( $p=0.006)$, a 95\% confidence interval (1.54-131.82) [8]. All women had taken antiretroviral triple therapy as part of mother-child prevention of HIV transmission with an average CD4 cell count at 416/ $\mathrm{mm}^{3}$, viral load was not available. The maculopapular exanthema is the predominant clinical form during the nevirapine toxidermia; the severe forms represent 4 and 9\% [2]. The imputability of nevirapine by the French method was very likely [9]. The favorable outcome in all our patients could be related to the young age, the absence of factors of co morbidities, the stoppage of the ARV and the multidisciplinary early management (between dermatologist and obstetricians). We did not observe fetal complications to the type of prematurity that is reported by some authors [10-12]. Anti-proteases were used as a therapeutic alternative in the antiretroviral treatment protocol because nevirapine toxidermia is associated with a $10 \%$ cross-reactivity risk with efavirenz.

\section{Conclusion}

The Nevirapine is the most widely accused drug during antiretroviral. These toxidermias are severe during pregnancy with high maternal and fetal mortality and a risk of prematurity in the newborn. The replacement of nevirapine with an anti-protease is a therapeutic alternative in our resource-limited countries.

\section{References}

1. Ngambi PG, Kalungia AC, Law MR, Kalemeera F, Truter I, et al. (2017) Evidence on the cost-effectiveness of lifelong antiretroviral therapy for prevention of mother-to-child transmission of HIV: Implications for resource-limited countries in sub-Saharan Africa. Expert Rev Pharmacoecon Outcomes Res 11: 1-9. 
Citation: Diatta BA, Gassama O, Diadie S, Diallo M, Niang SO, et al. (2017) Stevens Johnson Syndrome and Toxic Epidermal Necrolysis Induced by Nevirapine among HIV-Infected Pregnant Women: Five Cases. J AIDS Clin Res 8: 724. doi: 10.4172/2155-6113.1000724

2. Pitche P, Drobacheff-T C, Gavignet B, Mercier M, LaurentR (2005) Toxidermie à la névirapine: Étude des facteurs de risque chez 101 malades infectés par le VIH. Ann Dermatol Venereol 132: 970-974

3. Bourezane Y, Salard D, Hoen B, Vandel S, Drobacheff C, et al. (1998) DRESS (drug rash with eosinophilia and systemic symptoms) syndrome associated with nevirapine therapy. Clin Infect Dis 27: 1321-1322.

4. Metry DW, Lahart CJ, Farmer KL, Hebert A (2001) Stevens-Johnson syndrome caused by the antiretroviral drug nevirapine. J Am Acad Dermatol 44: 354-357.

5. Sabyasachi P, Sukanta S, Nikhil E, Bibhuti S, Santanu KT (2016) Fatal nevirapine-induced toxic epidermal necrolysis in a HIV infected patient. J Clin Diagn Res 10: 3-6.

6. Struck MF, Illert T, Liss Y, Bosbach ID, Reichelt B, et al. (2010) Toxic epidermal necrolysis in pregnancy: Case report and review of the literature. J Burn Care Res 31: 816-821.

7. Esau CJ, Guilherme AC, Menezes JA, D'Ippolito MM, Cruz ML, et al. (2006) Nevirapine toxicity in a cohort of HIV-1 infected pregnant women. Am J Obstet Gynecol 194: 199-202.
8. Dube N, Adewusi E, Summers R (2013) Risk of nevirapine-associated Stevens-Johnson syndrome among HIV-infected pregnant women: The Medunsa National Pharmacovigilance Centre, 2007-2012. S Afr Med J 103: 322-325.

9. Bégaud B (1985) Imputabilité des effets inattendus ou toxiques des médicaments: Actualisation de la méthode utilisée en France. Therapie 40: 111-118.

10. Knight L, Todd G, Muloiwa R, Matjila M, Lehloenya RJ (2015) Stevens Johnson syndrome and toxic epidermal necrolysis: Maternal and foetal outcomes in twenty-two consecutive pregnant HIV infected women. PLoS ONE 10: e0135501.

11. Rodriguez G, Trent JT, Mirzabeigi M, Zaulyanov L, Bruce L, et al. (2006) Toxic epidermal necrolysis in a mother and fetus. J Am Acad Dermatol 55: 96-98.

12. Dong BJ, Zheng Y, Hughes MD, Frymoyer A, Verotta D, et al. (2012) Nevirapine pharmacokinetics and risk of rash and hepatitis among HIV-infected subSaharan African women. AIDS 26: 833-841. 